\title{
Experimental characterization of longitudinal mechanical properties of clear timber: Random spatial variability and size effects
}

\author{
Alireza Farajzadeh Moshtaghin ${ }^{1}$, Steffen Franke ${ }^{2}$, Thomas Keller ${ }^{1}$ and Anastasios P. \\ Vassilopoulos $^{1 *}$ \\ ${ }^{1}$ Composite Construction Laboratory (CCLab), Ecole Polytechnique Fédérale de Lausanne (EPFL), \\ Station 16, Bâtiment BP, CH-1015 Lausanne, Switzerland \\ ${ }^{2}$ Timber and Composite Construction, Bern University of Applied Sciences, Solothurnstrasse 102, \\ Biel, Switzerland
}

\begin{abstract}
In this study, an experimental campaign was conducted to characterize the length effect on the elasticity and tensile strength of clear spruce wood parallel to the grain direction. Four groups of specimens of different lengths, cut from the same log, were tested under the same conditions under longitudinal tensile loading. The cross-sectional area of the specimens was selected as being constant and sufficiently small to exclude the effect of variations of the properties in the transverse direction. Local deformations along the lengths of the specimens were recorded during the tests in order to characterize the spatial variability of the elastic modulus. A connection between the mesostructure of the clear wood and its local elastic modulus was observed. Statistics concerning the elastic modulus, strength and strain to failure and the effect of length change on these properties were extracted. The strength statistics were also used to examine the accuracy of the classical Weibull size effect law. The correlations between the strength, the elasticity and the density were obtained. The results show a variability of approximately $20 \%$ in the local elastic modulus. Also, the variability of the effective elastic modulus decreases with increasing length. The mean value of the strength has an upper bound when the length approaches zero, in contrast to the Weibull law, while its variability remains virtually unchanged for different lengths.
\end{abstract}

Keywords: clear wood, size effect, mechanical properties, spatial variability, tensile tests

\footnotetext{
${ }^{*}$ Corresponding Author: e-mail: anastasios.vasilopoulos@epfl.ch Tel.: +41 216936393 Fax: +41 216936240.
} 


\section{Introduction}

As a natural unidirectional fiber composite, wood/timber has highly anisotropic properties [1]. Different factors such as age, location of timber within the tree, structural imperfections, load history such as wind and snow etc. can affect the material properties of timber taken from the same species, and grown in the same geographical location and local growth conditions. Consequently, there is a considerable variability in mechanical properties. This variability, also observed in other materials such as composites, is both random and spatial and is usually referred to as "random spatial variability" [2-3].

The effect of the high scatter of timber elastic properties [4] on the response of timber structures has received less attention in the literature than the effect of the scatter of strength. In the few works that take the statistical variability of the elastic modulus into account, when assessing the structural response, the local point-by-point variability, i.e. the spatial variability, is commonly neglected $[5,6]$. This local variability of the elastic modulus can affect the local stress state of the material, which can be critical in estimating the failure probability under external loading. Recently Arwade et al. [7] have experimentally characterized the longitudinal spatial variability in the elasticity of parallel strand lumber using bending tests. They incorporated the experimental results in a stochastic model with orthotropic elasticity.

The mean strength of timber decreases as its volume increases due to the size effect on the strength. A small number of works have used pure tensile tests, on specimens of different sizes, to investigate the size effect on the strength of clear timber. In [8], a length effect parameter was introduced by Zhu et al. to quantify the size effect, due to the length change, on the longitudinal tensile strength of Japanese larch wood. Dill-Langer et al. [9] conducted longitudinal tensile experiments on two groups of specimens composed of spruce wood, and observed that the volume of the material significantly affects the strength. The term clear timber in this paper is equivalent to clear wood suitable for building and construction.

The classical Weibull size effect law (CWSEL) [10] is commonly used in the literature for modeling this effect $[5,6,9]$. Some researchers have considered this effect as a volume effect. For example, this assumption was applied in [11-14] for the failure analysis of adhesivelybonded, welded and dovetail timber joints and in [5,6,15] for the study of the elastoplastic behavior of strand-based wood composites and laminated veneer. Others, however, have split this effect into length and cross-sectional effects, see e.g. [16,17] on the bending strength of clear timber and [18] for the case of structural lumber. Nevertheless, in a recent study [19], it 
was highlighted that "Although no conclusive evidence has yet arisen concerning the accuracy of probabilistic strength theories to describe the size in the strength of timber, the existence of significant size effects is largely accepted within the scientific community."

The spatial variability is most likely to influence the response of structural elements made of clear timber, such as bonded and mechanical joints, which has not been previously studied. This work is an attempt to investigate the random spatial variability of the timber elastic modulus. Also, it is partly aimed at experimentally characterizing the size effect on the strength of clear timber using specimens of different lengths, which can be used for developing more accurate models for the size effect on timber strength. This work is focused on clear timber properties at mesoscale and does not investigate the properties of timber boards with defects.

Four groups of specimens of different lengths were prepared and their quasi-static behavior was experimentally investigated under tensile loading. In addition to the global displacement monitoring, the local deformations along the length of each specimen were measured. The effect of the mesostructure of the clear timber on the local elastic modulus was examined. The spatial variability of the elastic modulus was experimentally characterized. Also, Statistics concerning the elastic modulus, strength and strain to failure as well as correlations between elastic modulus, strength and density were derived. Moreover, the size effect on these properties due to the length change was studied.

\section{Experimental investigation}

\subsection{Material}

Norway spruce wood was used for the specimens' preparation in this study. Although the boards contained a certain number of knots, the specimens were cut sufficiently far from these defects. All specimens were conditioned to $12 \%$ moisture content according to the ASTM standard D143-14 in a conditioning chamber and were tested at the laboratory temperature of $22 \pm 3{ }^{\circ} \mathrm{C}$. The average density of the wooden specimens after conditioning was $443.3 \mathrm{~kg} / \mathrm{m}^{3}$.

\subsection{Specimen description}

Specimens of different lengths were fabricated for the purpose of this study. In order to exclude variations in the properties in the cross-sectional plane, the nominal cross section of the specimens had to be as small as possible and yet it had to be possible to fabricate them well using a CNC machine. Due to these requirements, a new specimen geometry for longitudinal 
tensile tests on timber was designed. This geometry is shown in Fig. 1. The gradual change in the dimensions of the cross-sectional area, from the gripping part to the middle part, via two connected curves, provides an appropriate smooth stress distribution. Moreover, this specimen is easy to fabricate since it has an extruded geometry.

The specimen's geometrical configuration is shown in Fig. 2a. The cross section of the middle part is a square of $2 \times 2 \mathrm{~mm}^{2}$. In Fig. 2a, L denotes the length of the middle zone of the specimen with the values of 2, 8, 32 and $128 \mathrm{~mm}$. Sample specimens are shown in Fig. 2b. Specimen edges were carefully treated with very soft sandpaper, P240, to remove the cutting residual.

The following system is used to refer to the specimens in this study: LT-abc-4-de where 'LT' refers to longitudinal tensile, 'abc' is the specimen length in mm, 4 is the cross-sectional area in $\mathrm{mm}^{2}$ and 'de' is the specimen number within a group of specimens with the same geometry. In the next sections, it is seen that the strengths of the four specimen sets with different lengths, although cut from different boards, show approximately the same level of scatter. This demonstrates that a sufficient number of specimens in each group have been considered to capture the randomness of the properties of the material used.

\subsection{Experimental set-up and instrumentation}

All experiments were carried out on a 25-kN MTS Landmark servo-hydraulic testing machine with a built-in load cell calibrated to $20 \%$ of the full capacity. Quasi-static tensile tests were performed under displacement-control mode. Different stroke rates for different lengths were selected on the basis of the pre-testing of additional specimens so that the final failure occurred within $180 \pm 60 \mathrm{~s}$ during the whole testing program. A constant stroke rate among different groups was not used because the specimen sizes were different. Due to the scatter in the strength and stiffness, the failure time varied for specimens with the same geometry.

A video extensometry system composed of a 10-bit Sony XCLU1000 CCD connected to a Fujinon HF35SA-1 lens, with a focal length of 35-mm and an aperture, f 1.4-22, able to provide an accuracy of $\pm 0.005 \mathrm{~mm}$, was used during the tests to measure the axial deformation. Prior to the tests, small black target dots of 1.3-mm in diameter were applied on the specimens' surfaces as shown in Fig. 3 for a specimen of $32 \mathrm{~mm}$-length. The distance between each two consecutive dots was $4 \mathrm{~mm}$ for all groups of specimens, except for specimens with a nominal length of 2 $\mathrm{mm}$, where the distance between the two dots was $2 \mathrm{~mm}$. The axial coordinates of the dots were recorded at a frequency of $5 \mathrm{~Hz}$ by the camera throughout loading. Using these data, the strain 
between each two consecutive dots was calculated. The axial stresses were also calculated using the load level and the initial cross-sectional area.

\section{Timber mesostructure and local mechanical properties}

The mesostructure of clear spruce wood is mainly characterized by the earlywood-latewood patterns which affect the local mechanical properties. This is the origin of random spatial variability in the properties. Some of these mesostructural features observed in the specimens are shown in Fig. 4. The darker parts of the growth rings are latewood that has higher mechanical properties, referred to as strips of latewood. Although all the specimens were cut in the nominal longitudinal direction of the board, the fiber direction along the specimen length is often not parallel to the specimen axial direction. Figure 4a illustrates the fiber misalignment with respect to the nominal longitudinal direction of the board. This misalignment can reduce the local longitudinal elastic modulus, however, it is not related to the specimen misalignment, since all specimens were cut parallel to the nominal longitudinal axis of the timber boards. Another consequence is that at some points along the length of a specimen a new strip of latewood or an existing strip may cross the specimen border. This is the main cause of sudden changes in the local elastic modulus. Figure $4 \mathrm{~b}$ exhibits another feature that can affect the local elastic modulus. The distance between two consecutive strips of latewood, or growth ring thickness, is smaller in Fig. 4b than that in Fig. 4a. The decrease in thickness increases the local density which, in turn, can increase the local elastic modulus, and vice versa. In the current study, it may also lead to an increase in the number of latewood strips in the same cross section. Finally, Fig. $4 \mathrm{c}$ shows the fiber waviness that tends to reduce the value of the local elastic modulus.

Typical examples of the correlation between the local elastic modulus and the local mesostructure of spruce wood are given in Fig. 5, considering two specimens of 128-mm length. In specimen LT-128-4-06, it can be seen that, initially, there is an obvious fiber misalignment that gradually diminishes so that the fiber becomes parallel to the nominal axis of the specimen. Subsequently, the fiber starts to deviate from the nominal axis again. Correspondingly, the local elastic modulus generally first increases and then decreases. In specimen LT-128-4-07, there is an obvious fiber waviness over the first few millimeters of the length, which is why the local elastic modulus suddenly increases from 8.0 GPa to 13.0 GPa. 
The spatial variability of the elastic modulus along the length is examined here for specimens of 128-mm length. This involves 40 sets of 32 data points, each set being collected from a single specimen. The values of the local elastic modulus are shown in Fig. 6. The three solid horizontal lines show the range of values $11.0 \pm 1.4 \mathrm{GPa}($ mean $\pm \mathrm{SD})$. Also, the spatial variability of three indicative specimens are highlighted via the thicker lines. It can be seen that the variability in some specimens is lower along their lengths and the local elastic modulus oscillates around the effective elastic modulus of the specimen; see for example the dashed and dotted lines corresponding to specimens LT-128-4-05 and LT-128-4-09. On the other hand, some specimens exhibit more significant changes in their local modulus, e.g. from $15 \mathrm{GPa}$ to $7 \mathrm{GPa}$, approximately, shown by the thick solid line corresponding to specimen LT-128-4-04. Also, Fig. 6 shows that the measured value of the local elastic modulus was $21.1 \mathrm{GPa}$ at one point in specimen LT-128-4-20. This was because in that region of the specimen, two strips of latewood happened to be almost parallel to the nominal axis of the specimen. The corresponding segment of the specimen is shown by a yellow circle in Fig. 7. The local modulus of the segment on the right has a lower value of $18.6 \mathrm{GPa}$, which is because some of the latewood crosses the specimen border in this segment.

Specimen failures can be roughly categorized into two different forms, schematically shown in Fig. $8 \mathrm{a}$ and $\mathrm{b}$. The first form is a failure that exhibits a sharp angle between each face of the fracture zone and the nominal axis of the specimen. In the second form, however, the angle is more open, and the fracture faces are frequently more uneven than in the first case. Generally, the specimens with a failure form of the first category had higher strength values. For example, eight out of 10 specimens, of 128-mm length, with the highest strength values fell into the first category. On the other hand, seven out of 10 specimens with the lowest strength values fell into the second category. Examples of these two forms are shown in Fig. 8c and d. There was always some degree of misalignment in the specimens, and the fracture path did not cross the latewood in most cases. As a result, in cases with less misalignment, the fracture surface was larger, which naturally required higher forces for fracture initiation. The observation that higher and lower strengths were not always associated with first and second failure forms, respectively, is attributed to the fact that microdefects may also influence specimen strength. 


\section{Mechanical behavior of specimens}

Typical tensile stress-strain curves are shown in Fig. 9. These curves have been obtained directly using the axial displacements of the two end dots. Therefore, the slope of each curve indicates the elasticity of the whole nominal length of the corresponding specimen, referred to as the effective elastic modulus in the current study. The term 'effective' is used to distinguish it from local elastic modulus. It is seen that the mechanical behavior is linear up to failure. The high scatter in the strength and the effective elastic modulus of the specimens can be clearly seen in this figure. The elasticity of a specimen segment between two consecutive dots is the local elastic modulus which is attributed to the center of the segment.

Each specimen can be considered as a set of series of springs, with each segment, between two consecutive dots, corresponding to a spring. The measured values for the local elastic moduli were used to calculate the value of the effective elastic modulus of the specimen, based on the concept of the series of springs, using the following formula:

$$
\frac{n}{E_{e f f}}=\frac{1}{E_{1}}+\frac{1}{E_{2}}+\ldots+\frac{1}{E_{n}}
$$

in which $E_{\text {eff }}$ is the effective elastic modulus of the specimen and $E_{i}(i=1,2, \ldots, n)$ are the local elastic moduli. The value of $E_{\text {eff }}$, computed using Eq. (1), was compared to that obtained by using the end-dot displacements. The difference was less than $0.1 \%$ in all specimens, which confirmed the accurate measurement of the local elastic moduli, since any significant error in the measured values for the local moduli would result in a significant error in the value for the effective elastic modulus, calculated based on the concept of series of springs. Also, it can be mathematically proven that $E_{\text {eff }}$ from Eq. (1) is always smaller than the arithmetic average of $E_{i}^{\prime} \mathrm{s}\left(\sum_{i=1}^{n} E_{i} / n\right)$.

The mechanical properties of each specimen including the effective elastic modulus, the strength and the strain to failure, as well as their density, are given in Table 1 . The density was obtained by dividing the weight of each specimen by its volume, after conditioning as mentioned earlier. Certain sections of the table contain dashes because some specimens did not fail in the middle part with constant cross section, or, in some cases, there were problems in recording the deformation during the tensile experiments. 


\section{Statistics concerning elastic modulus, strength and strain to failure}

\subsection{Statistics concerning elastic modulus}

The statistics concerning the effective elastic modulus for the four groups of specimens are shown in Table 2. It can be seen that the mean value does not change significantly with increasing length and is in agreement with the reported value of $11.0 \mathrm{GPa}$ in the literature [1] for the longitudinal elastic modulus of spruce wood. The mean values and the corresponding standard deviations are plotted in Fig. 10. The mean effective elastic moduli of specimens of longer lengths have slightly higher values. The difference between the mean values of the shortest and longest specimens is $6.4 \%$. The standard deviation (SD) significantly decreases from the shortest to the longest specimens. The coefficient of variation (COV) is almost the same for 2-mm and 8-mm specimens. With increasing length, the COV starts to diminish, decreasing from a value of $19.6 \%$ for $2-\mathrm{mm}$ specimens to $12.7 \%$ for $128-\mathrm{mm}$ specimens. Fig. 11 shows the COV of the effective elastic modulus vs. the specimen length in a logarithmic scale. It can be seen that the COV approaches a constant value for very small lengths, which can be considered as an upper bound for the COV of the longitudinal tensile modulus in the length range examined. This is attributed to the spatial correlation in the elastic modulus field. In other words, from a length of $2 \mathrm{~mm}$ to $8 \mathrm{~mm}$, the spatial correlation remains at a high level, with the modulus statistics remaining the same. The reduction of the variability in the effective elastic modulus with increasing length can be explained by considering each larger specimen as a series of smaller specimens. Naturally, the variability in the effective elastic modulus is reduced for the longer specimen, because the elasticity of each smaller specimen contributes to the elasticity of the larger specimen.

The presence of scatter in the mechanical properties of timber leads to uncertainty regarding the response of timber structures. For probabilistic modeling of timber structures, it is necessary to know the statistical distribution governing the mechanical properties. The three most commonly used statistical distributions for mechanical properties, i.e. normal, lognormal and Weibull, were fitted to the experimental data for the four groups of specimens. The results of the goodness-of-fit tests, Anderson-Darling (AD) and Kolmogorov-Smirnov (KS), at a significance level of 0.05 are given in Table 3. A 'zero' denotes that sampled data are taken from the corresponding distribution, while 'one' rejects the presumed distribution. It can be seen that the tests support these statistical distributions for all four groups of specimens, except for the AD test in the case of the Weibull distribution. Therefore, both normal and lognormal distributions can represent the statistical variability of the elastic modulus in stochastic 
simulations of timber structures. From a computational point of view, using the normal distribution is preferable as it is simpler to implement.

The mean value, SD and COV of the collected data points for the local elastic modulus (corresponding to a total of 1280 segments with 4-mm length) are compared to those of the effective modulus of the 128-mm specimens in Table 4. The mean value of the local moduli, 11.2 $\mathrm{GPa}$, is slightly higher than the mean value of the effective moduli, $11.0 \mathrm{GPa}$. This is because the effective modulus of each specimen is calculated using the values of the local modulus based on the concept of series of springs, shown in Eq. (1). The COV of the local modulus, $16.4 \%$, is also higher than that of the effective modulus, $12.7 \%$, due to the averaging that occurs during calculation of the effective modulus, which tends to reduce the scatter.

Further, from Fig. 11, a COV of $19.8 \%$ for the elastic modulus of the specimens of $4-\mathrm{mm}$ lengths can be obtained using the fitted curve. This value is larger than the COV of the local moduli, 16.4\% (see Table 4) obtained from 4-mm segments. This difference in the COV is attributed to the fact that the data in Fig. 11 are obtained from independent specimens; however, the COV for the 4-mm segments of 128-mm specimens is obtained based on the data points that are not totally independent. There is a spatial correlation within each set of 32 values for the local elastic modulus obtained from a single specimen. This spatial correlation leads to a reduction of scatter when the 40 sets of 32 data points are considered collectively.

Two types of variability contribute to the ensemble COV of $16.4 \%$ for the mentioned 1280 data points, taken from the 4-mm segments of the 128 -mm specimens. The first, designated withinspecimen variability, is the $\mathrm{COV}$ of the 32 data points for the local elastic moduli in a single specimen of 128-mm length. The mean value of these $40 \mathrm{COVs}$, corresponding to 40 specimens of 128 -mm length, is equal to $9.7 \%$, which represents the average variability of the local elastic modulus in each specimen. The second, designated between-specimen variability, is the COV of the 40 values for the effective elastic moduli of the 40 specimen of 128 -mm lengths. The value of the between-specimen variability is $12.7 \%$, as given in Table 2. Therefore, the contribution of the between-specimen variability to ensemble variability is more than that of the within-specimen variability for the considered specimen length.

\subsection{Statistics concerning longitudinal tensile strength}

The statistical characteristics for the longitudinal tensile strength of spruce wood are given in Table 5 for the four groups of specimens. It can be seen that, as the length increases from $2 \mathrm{~mm}$ to $8 \mathrm{~mm}$, the change in the mean value of the strength is negligible. As the length increases 
further, the mean strength starts decreasing. This decrease is more significant between the 32$\mathrm{mm}$ and $128-\mathrm{mm}$ specimens. The COV of the strength does not change significantly as the specimen length increases. In Table 5, from a length of $2 \mathrm{~mm}$ to a length of $32 \mathrm{~mm}$, the COV increases a little and then decreases a little for 128-mm specimens. Therefore, an average value of $15.1 \%$ is considered as representing the scatter in the longitudinal tensile strength of spruce wood, which is independent of specimen length. Such a difference in the COVs for specimens of different sizes was observed in a previous study [9] for two different volumes of spruce wood.

In Figs. 12 and 13, the mean values and COVs for the strengths of the four specimen groups have been plotted against their lengths in the logarithmic scales, respectively. The solid blue line is a fitting curve in Fig. 12. Comparing this curve with that in Fig. 11, it can be seen that the COV of the stiffness and the mean value of the strength vary in more or less the same way as the length increases. This might suggest that both of these properties may be modeled using the same theory, such as the theory of stochastic processes [20]. The difference is that as the size increases the previously mentioned averaging for the elastic modulus tends to decrease its $\mathrm{COV}$, while its mean value remains almost unchanged, whereas the weakest link concept, which governs the fracture of brittle materials, tends to decrease the mean value of the strength, while the COV remains almost unchanged.

In the reliability analysis of clear timber structural elements, such as bonded joints, based on ultimate limit states, accurate representation of the variability in strength via a statistical distribution is critical. Commonly used statistical distributions for mechanical properties in the literature, i.e. Weibull, normal and lognormal, were fitted to the experimental data for the longitudinal strength. The results of $\mathrm{AD}$ and KS tests are given in Table 6. Both tests support Weibull and normal distributions, but the AD test rejects lognormal distribution for 128-mm specimens. However, it is generally accepted that the Weibull distribution is the best one for representing variability in the strength of brittle materials where it also has a physical meaning.

\section{Comparison of experimental results with CWSEL prediction}

According to the CWSEL for the failure of brittle materials, which is still widely used $[5,6,9$ $15,19,21]$, as the volume of the material decreases, the mean strength increases following a straight line with a constant slope in logarithmic scales. Therefore, when the volume approaches zero, an unbounded value is predicted for the strength. However, the experimental results in the current study show that as the volume decreases, the mean value approaches a constant value 
of 113.0 MPa, which is the upper bound value for the mean strength of spruce wood used in this study.

In order to quantitatively examine the error involved in the prediction of the CWSEL, the following formula was used [12]:

$$
\frac{\bar{\sigma}_{1}}{\bar{\sigma}_{2}}=\left(\frac{V_{2}}{V_{1}}\right)^{1 / m}
$$

where $m$ is the shape factor of the Weibull distribution. The average value of $15.1 \%$ for the $\mathrm{COV}$ of the strength leads to a value of 7.85 for the Weibull shape factor. A shape factor of 8.3 was reported in [9] for specimens of nominal dimensions $2 \times 6 \times 35 \mathrm{~mm}^{3}$. In Table 5, mean values predicted by CWSEL are also provided, considering the nominal volume of a specimen of 128 $\mathrm{mm}$ length as reference volume. Compared to the experimental results, the predicted values are $11.0 \%, 30.8 \%$ and $56.2 \%$ for specimens of 32-mm, $8-\mathrm{mm}$ and $2-\mathrm{mm}$ lengths, respectively. These calculations show that the CWSEL overestimates the effect of size on strength, although the statistical variability of the strength within each group of specimens can be described well via the Weibull distribution with the same shape factor.

\subsection{Statistics concerning strain to failure}

The statistical variability in the strain to failure for the four groups of specimens is examined here. Table 7 shows the statistics for the mean value, SD and COV of the tensile strain to failure of spruce wood in the longitudinal direction. The mean value is slightly reduced as the length increases, from $1.14 \%$ for $2-\mathrm{mm}$ length to $0.96 \%$ for $128-\mathrm{mm}$ length. This reduction is attributed to the fact that longer specimens have a lower mean strength while exhibiting a similar mean effective elastic modulus. The reduction of the SD is more significant with increasing length leading to a reduction in the COV of the strain to failure, except between 32$\mathrm{mm}$ and 128-mm lengths. This may be because the statistics for both elastic modulus and strength affect the statistics for the strain to failure, leading to a trend change in the COV of the strain to failure.

Some stochastic problems are better formulated in terms of strain to failure rather than strength [22]. In these cases, the type of distribution representing the statistical variability of the strain to failure is important. Table 8 shows results of the goodness-of-fit tests for the strain to failure. The AD and KS tests support the normal and lognormal distributions as being representative of 
the statistical variability of the strain to failure. The Weibull distribution is rejected by the AD test for 32-mm specimens.

\section{Correlations}

Figure 14 shows the tensile strength of each specimen vs. the corresponding local elastic modulus measured at the failure zone. In this figure, the data from each of the four specimen groups are indicated by a different symbol. Also, the centroid of each group is indicated via a larger symbol of the same type, and the average regression line (solid line) is shown. No significant difference between the scatter in the results of the four groups can be observed, except for 128-mm specimens, which have a lower mean value for the strength. The linear correlation coefficient was found to be 0.686 . This is an important parameter for modeling the variability of the mechanical properties in timber structures. For example, when in a finite element model, a value is randomly assigned to the elastic modulus, the variability of the distribution, based on which a value is randomly assigned to the strength at that material point, is reduced. This reduction of variability depends on the level of the correlation; e.g., when the correlation coefficient is 1 , there remains no variability for the second parameter.

Figures 15 and 16 show the effective elastic moduli and the strengths versus the densities, respectively, for the four specimen groups based on which correlation coefficients of 0.696 and 0.580 were obtained. The larger symbols indicate the centroids of the specimen groups, while the average regression line is also given. The mean values of the densities for specimens of different lengths are approximately the same. The mean value, SD and COV of the density of the spruce are $443.3 \mathrm{~kg} / \mathrm{m}^{3}, 39.0 \mathrm{~kg} / \mathrm{m}^{3}$ and $8.8 \%$, respectively. The correlations between the density and the mechanical properties are used in seismic and acoustic applications where dynamic forces are present.

\section{Conclusions}

In this study, an experimental campaign consisting of the longitudinal tensile tests on the four groups of specimens composed of spruce wood was conducted. The total number of specimens 
was 165 . The nominal length of specimens varied from $2 \mathrm{~mm}$ to $128 \mathrm{~mm}$ in order to investigate the effect of length on the elasticity and strength. The cross-sectional area was the same for all specimens and sufficiently small as to exclude the effect of the variability of properties in the transverse plane and to find the upper bound values for the investigated properties. The following main conclusions were drawn:

- The new specimens with the extruded geometry proposed for tensile tests on timber are simple and efficient because they are easy to fabricate, and the failure in almost all specimens occurred in the middle part with a constant cross-sectional area.

- The main reason for the spatial variability of the local elastic modulus is irregular changes in the mesostructure of the wood including fiber misalignment, fiber waviness and growth ring thickness.

- Specimens with higher strength levels tend to fail in such a way that the fracture surfaces form a sharper angle to the axial direction than those of specimens with lower strength levels, which is attributed to the latewood pattern around the failure zone. The failure was brittle for all specimens.

- Considerable spatial variability in the local elastic modulus was observed along specimen lengths. The contribution of the between-specimen variability to the ensemble variability is greater than that of the within-specimen variability for the examined specimen length.

- The COV of the effective elastic modulus in the parallel-to-grain direction has an upper bound of ca. $20 \%$ when the length is very small due to spatial correlation in the elastic modulus field and decreases to $12.7 \%$ for a length of $128 \mathrm{~mm}$. The mean value does not change significantly.

- An upper bound value of 113.0 MPa was obtained for the mean value of the longitudinal tensile strength when the length is very small. The existence of the upper bound is again due to the spatial correlation of the strength field. The mean value decreased to 103.8 $\mathrm{MPa}$ for a length of $128 \mathrm{~mm}$. The change in the COV of the tensile strength with specimen length was negligible, with an average value of $15.1 \%$. The variation of the mean strength with specimen size cannot be appropriately modeled by the CWSEL.

With recent progress in computational power, more advanced stochastic analyses of clear timber structural elements, such as bonded and mechanical joints, are feasible. As has been shown, the mechanical properties of clear timber are spatially variable in a random manner. The random field approach can take the random spatial variability of material properties into 
account. Therefore, using this approach leads to more realistic models of timber structures. The results of this work are a preliminary step toward developing such stochastic models, and the current experimental results can substantially improve the prediction of the timber structures/components, such as timber joints, when used appropriately in a stochastic finite element framework.

\section{Acknowledgement}

The authors wish to acknowledge the funding of this work by the National Research Program NRP 66 of the Swiss National Science Foundation (Grant No. 406640-136680).

\section{References}

[1] Dinwoodie, J.M., 2000. Timber: Its nature and behaviour. Taylor \& Francis Group.

[2] Vořechovský, M., 2007. Interplay of size effects in concrete specimens under tension studied via computational stochastic fracture mechanics. International Journal of Solids and Structures 44, 2715 2731.

[3] Sriramula, S., Chryssanthopoulos, M.K., 2013. An experimental characterisation of spatial variability in GFRP composite panels. Structural Safety 42, 1-11.

[4] Forest Product Laboratory, 1999. Wood handbook: Wood as an engineering material, USDA, Madison, Wis.

[5] Clouston, P.L., Lam, F., 2002. A stochastic plasticity approach to strength modeling of strand-based wood composites. Composites Science and Technology 62, 1381-1395.

[6] Clouston, P.L., Lam, F., 2001. Computational modeling of strand-based wood composites. Journal of Engineering Mechanics 127, 844-851.

[7] Arwade, S.R., Clouston, P.L., Winans, R., 2009. Measurement and stochastic computational modeling of the elastic properties of parallel strand lumber. Journal of Engineering Mechanics 135, 897905.

[8] Zhu, J., Kudo, A., Takeda, T., Tokumoto, M., 2001. Methods to estimate the length effect on tensile strength parallel to the grain in Japanese larch. Journal of Wood Science 47, 269-274.

[9] Dill-Langer, G., Hidalgo, R.C., Kun, F., Moreno, Y., Aicher, S., Herrmann, H.J., 2003. Size dependency of tension strength in natural fiber composites. Physica A: Statistical Mechanics and its Applications 325, 547-560.

[10] Weibull, W., 1939. A statistical theory of strength of materials. In: Proceedings of the Royal Swedish Institute. Research No. 151, Stockholm, Sweden.

[11] Vallée, T., Tannert, T., Ganne-Chedville, C., 2012. Capacity prediction of welded timber joints. Wood Science and Technology 46, 333-347. 
[12] Tannert, T., Vallée, T., Hehl, S., 2012. Probabilistic strength prediction of adhesively bonded timber joints. Wood Science and Technology 46, 503-513.

[13] Tannert, T., Vallée, T., Hehl, S., 2012. Experimental and numerical investigations on adhesively bonded hardwood joints. International Journal of Adhesion and Adhesives 37, 65-69.

[14] Tannert, T., Lam, F., Vallée, T., 2011. Structural performance of rounded dovetail connections: Experimental and numerical investigations. European Journal of Wood and Wood Products 69, 471482.

[15] Clouston, P., Lam, F., Barrett, J.D., 1998. Incorporating size effects in the Tsai-Wu strength theory for Douglas-fir laminated veneer. Wood Science and Technology 32, 215-226.

[16] Madsen, B., 1990. Size effects in defect-free Douglas fir. Canadian Journal of Civil Engineering $17,238-242$.

[17] Madsen, B., Tomoi, M., 1991. Size effects occurring in defect-free spruce-pine-fir bending specimens. Canadian journal of civil engineering 18, 637-643.

[18] Madsen, B., 1990. Length effects in $38 \mathrm{~mm}$ spruce-pine-fir dimension lumber. Canadian Journal of Civil Engineering 17, 226-237.

[19] Tannert, T., Lam, F., Vallée, T., 2010. Strength prediction for rounded dovetail connections considering size effects. Journal of Engineering Mechanics 136, 358-366.

[20] Vanmarcke, E., 2010. Random fields: analysis and synthesis. World Scientific.

[21] Arwade, S.R., Clouston, P.L., Krupka, M.T., 2011. Length effects in tensile strength in the orthogonal directions of structural composite lumber. Journal of Testing and Evaluation 39, 1-7.

[22] Vořechovský, M., Chudoba, R., 2006. Stochastic modeling of multi-filament yarns: II. Random properties over the length and size effect. International Journal of Solids and Structures 43, 435-458. 
Table 1. Effective elastic modulus, strength, strain to failure and density for all tested specimens.

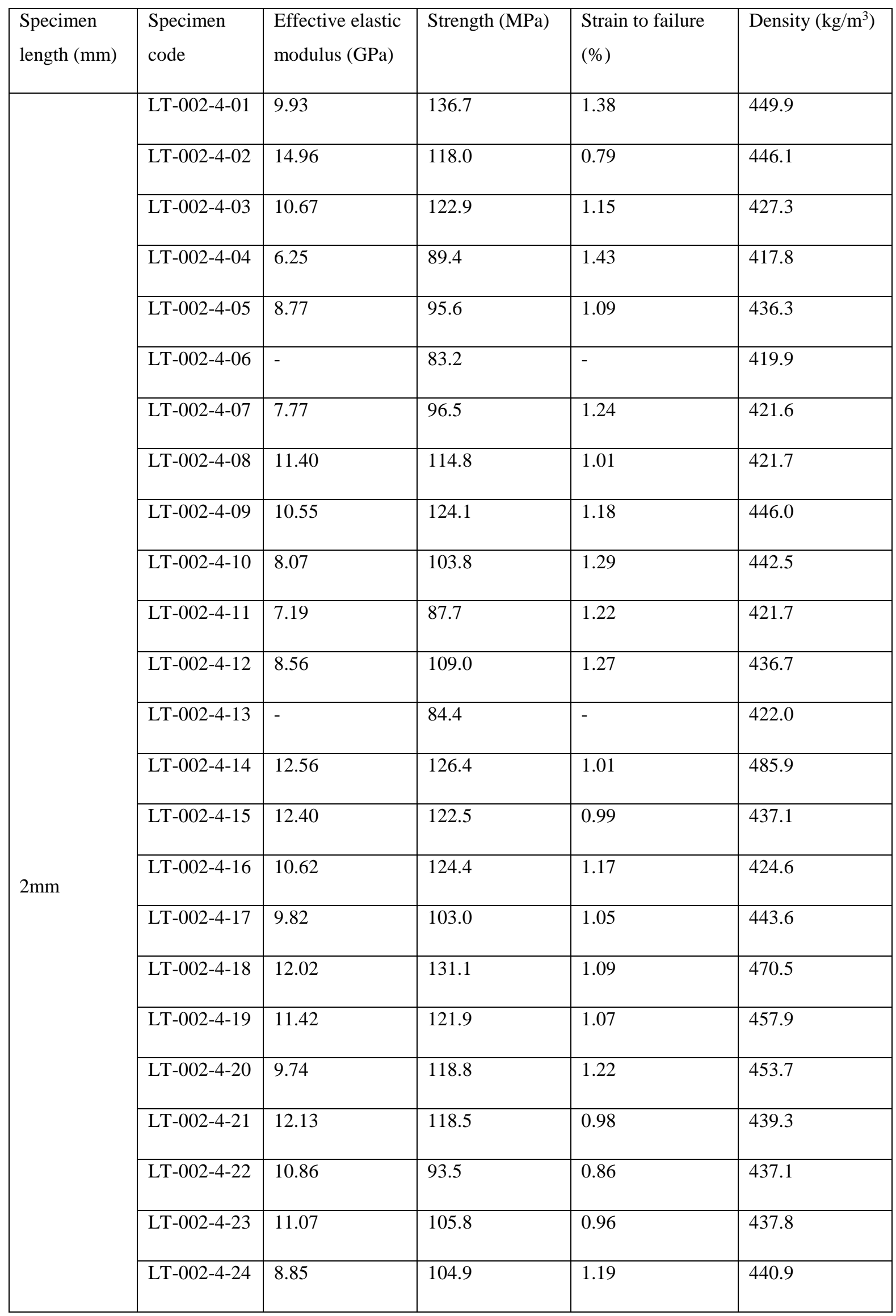




\begin{tabular}{|c|c|c|c|c|}
\hline LT-002-4-25 & 8.69 & 109.1 & 1.26 & 446.6 \\
\hline LT-002-4-26 & 6.62 & 108.1 & 1.63 & 450.9 \\
\hline LT-002-4-27 & 10.99 & 117.8 & 1.07 & 446.9 \\
\hline LT-002-4-28 & 14.05 & 132.0 & 0.94 & 475.9 \\
\hline LT-002-4-29 & 11.53 & 139.1 & 1.21 & 443.3 \\
\hline LT-002-4-30 & 11.48 & 117.7 & 1.03 & 453.3 \\
\hline LT-002-4-31 & 7.46 & 101.5 & 1.36 & 430.1 \\
\hline LT-002-4-32 & 10.35 & 117.7 & 1.14 & 443.1 \\
\hline LT-002-4-33 & 11.45 & 129.9 & 1.13 & 462.5 \\
\hline LT-002-4-34 & 8.70 & 111.4 & 1.28 & 429.8 \\
\hline LT-002-4-35 & 12.79 & 143.4 & 1.12 & 469.4 \\
\hline LT-002-4-36 & 10.29 & 87.5 & 0.85 & 451.9 \\
\hline LT-008-4-37 & 10.37 & 124.5 & 1.20 & 424.1 \\
\hline LT-008-4-01 & 11.10 & 110.1 & 0.99 & 429.0 \\
\hline LT-008-4-02 & 8.17 & 105.0 & 1.29 & 423.8 \\
\hline LT-008-4-03 & 11.91 & 103.6 & 0.87 & 455.8 \\
\hline LT-008-4-04 & 9.19 & 110.6 & 1.20 & 439.2 \\
\hline LT-008-4-05 & 9.53 & 115.0 & 1.21 & 455.7 \\
\hline LT-008-4-06 & 12.23 & 135.0 & 1.10 & 459.4 \\
\hline LT-008-4-07 & 9.28 & 91.9 & 0.99 & 411.8 \\
\hline LT-008-4-08 & 12.13 & 124.2 & 1.02 & 482.1 \\
\hline LT-008-4-09 & 9.07 & 100.2 & 1.11 & 438.5 \\
\hline LT-008-4-10 & 9.77 & 106.9 & 1.09 & 428.1 \\
\hline LT-008-4-11 & 9.89 & 103.8 & 1.05 & 433.0 \\
\hline LT-008-4-12 & 12.39 & 138.3 & 1.12 & 455.8 \\
\hline LT-008-4-13 & 8.94 & 118.3 & 1.32 & 426.1 \\
\hline LT-008-4-14 & 12.06 & 112.4 & 0.93 & 463.8 \\
\hline
\end{tabular}




\begin{tabular}{|c|c|c|c|c|c|}
\hline & LT-008-4-15 & 11.80 & 128.7 & 1.09 & 443.2 \\
\hline & LT-008-4-16 & 12.08 & 120.3 & 1.00 & 461.5 \\
\hline & LT-008-4-17 & 14.71 & 138.4 & 0.94 & 462.2 \\
\hline & LT-008-4-18 & 8.86 & 115.4 & 1.30 & 453.6 \\
\hline & LT-008-4-19 & 8.75 & 99.3 & 1.14 & 436.9 \\
\hline & LT-008-4-20 & 8.76 & 98.6 & 1.13 & 448.1 \\
\hline & LT-008-4-21 & 9.74 & 101.2 & 1.04 & 463.0 \\
\hline & LT-008-4-22 & 8.13 & 113.4 & 1.39 & 445.6 \\
\hline $8 \mathrm{~mm}$ & LT-008-4-23 & 7.81 & 85.2 & 1.09 & 431.8 \\
\hline & LT-008-4-24 & 6.94 & 91.2 & 1.31 & 447.1 \\
\hline & LT-008-4-25 & 10.38 & 120.8 & 1.16 & 440.3 \\
\hline & LT-008-4-26 & 7.11 & 101.0 & 1.42 & 417.8 \\
\hline & LT-008-4-27 & 11.43 & 144.5 & 1.26 & 453.6 \\
\hline & LT-008-4-28 & 8.97 & 86.5 & 0.96 & 434.8 \\
\hline & LT-008-4-29 & 8.36 & 103.8 & 1.24 & 439.0 \\
\hline & LT-008-4-30 & 7.51 & 83.1 & 1.11 & 421.9 \\
\hline & LT-008-4-31 & 8.84 & 123.4 & 1.40 & 445.5 \\
\hline & LT-008-4-32 & 10.36 & 115.5 & 1.11 & 470.6 \\
\hline & LT-008-4-33 & 10.20 & 123.5 & 1.21 & 463.8 \\
\hline & LT-008-4-34 & 9.38 & 92.7 & 0.99 & 435.3 \\
\hline & LT-008-4-35 & 9.51 & 87.3 & 0.92 & 433.2 \\
\hline & LT-008-4-36 & 13.21 & 137.6 & 1.04 & 461.5 \\
\hline & LT-008-4-37 & 9.82 & 119.3 & 1.21 & 453.8 \\
\hline & LT-008-4-38 & 8.80 & 106.6 & 1.21 & 450.6 \\
\hline & LT-008-4-39 & 10.65 & 117.2 & 1.10 & 434.4 \\
\hline & LT-008-4-40 & 13.03 & 147.3 & 1.13 & 478.1 \\
\hline & LT-008-4-41 & 13.39 & 131.5 & 0.98 & 458.4 \\
\hline
\end{tabular}




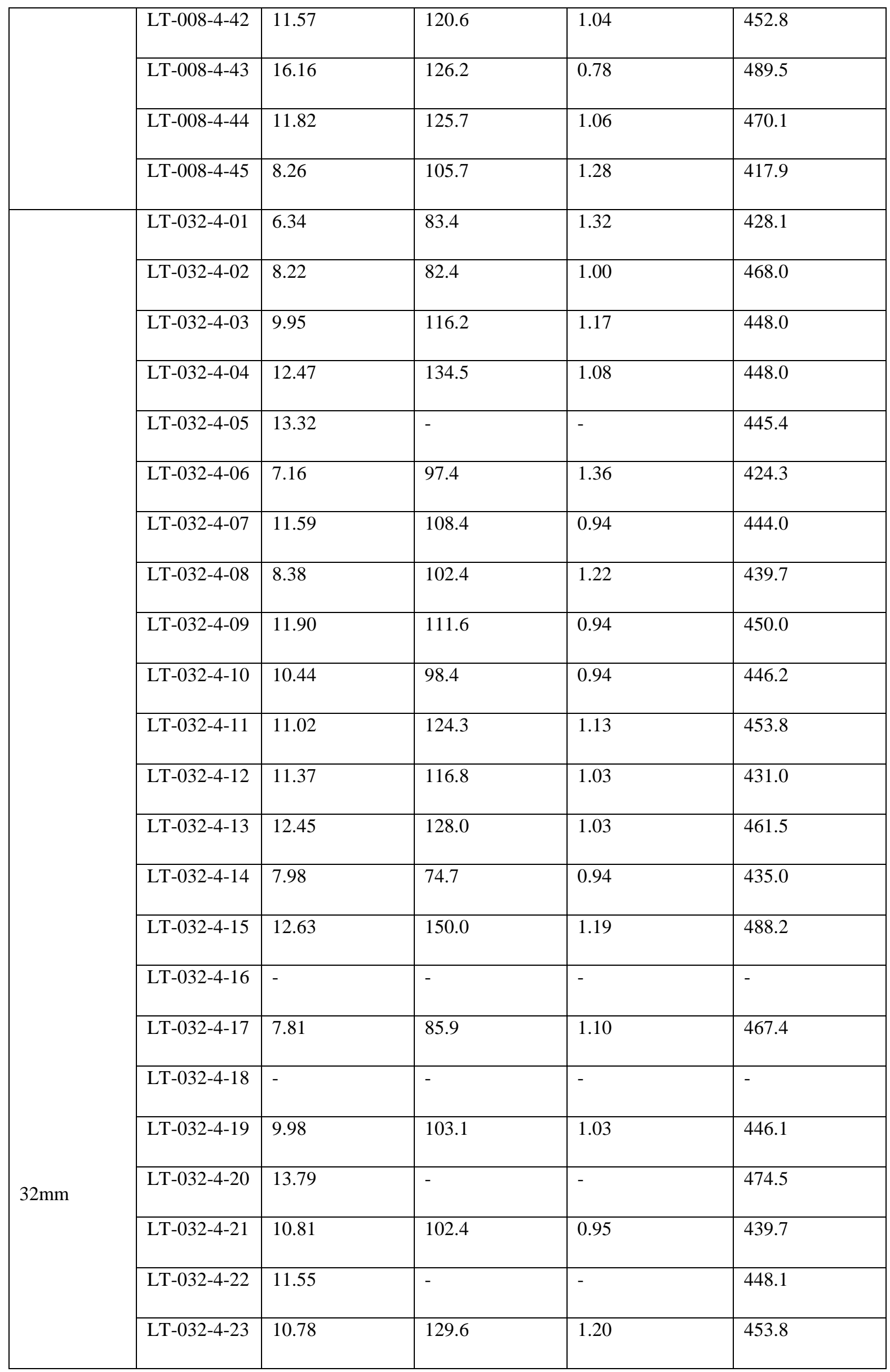




\begin{tabular}{|c|c|c|c|c|}
\hline LT-032-4-24 & 13.29 & 146.4 & 1.10 & 460.0 \\
\hline LT-032-4-25 & 12.64 & 125.7 & 0.99 & 449.6 \\
\hline LT-032-4-26 & 8.84 & 87.7 & 0.99 & 436.7 \\
\hline LT-032-4-27 & 12.52 & 137.4 & 1.10 & 452.7 \\
\hline LT-032-4-28 & 12.80 & 126.3 & 0.99 & 463.5 \\
\hline LT-032-4-29 & 11.79 & 110.0 & 0.93 & 453.9 \\
\hline LT-032-4-30 & - & - & - & - \\
\hline LT-032-4-31 & - & - & - & - \\
\hline LT-032-4-32 & 10.07 & 113.4 & 1.13 & 456.0 \\
\hline LT-032-4-33 & 8.16 & 100.0 & 1.23 & 424.3 \\
\hline LT-032-4-34 & 11.65 & 106.8 & 0.92 & 476.1 \\
\hline LT-032-4-35 & 9.55 & 94.4 & 0.99 & 452.7 \\
\hline LT-032-4-36 & - & - & - & - \\
\hline LT-032-4-37 & 9.46 & 110.8 & 1.17 & 429.8 \\
\hline LT-032-4-38 & 9.63 & 124.0 & 1.29 & 439.7 \\
\hline LT-032-4-39 & 10.36 & 120.8 & 1.17 & 437.8 \\
\hline LT-032-4-40 & 11.37 & 119.3 & 1.05 & 453.2 \\
\hline LT-128-4-01 & - & 105 & - & $\overline{441.4}$ \\
\hline LT-128-4-02 & - & 87.6 & - & 458.4 \\
\hline LT-128-4-03 & - & - & - & 462.7 \\
\hline LT-128-4-04 & 11.26 & 97.2 & 0.86 & $\overline{460.6}$ \\
\hline LT-128-4-05 & 13.48 & 136.0 & 1.01 & 457.4 \\
\hline LT-128-4-06 & 12.25 & 72.9 & 0.60 & 449.6 \\
\hline LT-128-4-07 & 11.88 & 110.7 & 0.93 & 440.8 \\
\hline LT-128-4-08 & 12.22 & 136.3 & 1.12 & 469.6 \\
\hline LT-128-4-09 & 8.31 & 90.9 & 1.09 & 439.1 \\
\hline LT-128-4-10 & 12.16 & 113.5 & 0.93 & 460.7 \\
\hline
\end{tabular}




\begin{tabular}{|c|c|c|c|c|c|}
\hline & LT-128-4-11 & 12.93 & 101.6 & 0.79 & 424.6 \\
\hline & LT-128-4-12 & 10.94 & 108.7 & 0.99 & 445.0 \\
\hline & LT-128-4-13 & 10.24 & 104.7 & 1.02 & 456.2 \\
\hline & LT-128-4-14 & 13.78 & 110.8 & 0.80 & 453.7 \\
\hline & LT-128-4-15 & 11.96 & 121.0 & 1.01 & 465.0 \\
\hline & LT-128-4-16 & 8.62 & 101.1 & 1.17 & 409.2 \\
\hline & LT-128-4-17 & 11.28 & 104.8 & 0.93 & 465.1 \\
\hline & LT-128-4-18 & 9.03 & 87.0 & 0.96 & 404.3 \\
\hline & LT-128-4-19 & 10.38 & 113.4 & 1.09 & 462.6 \\
\hline & LT-128-4-20 & 11.59 & 65.2 & 0.56 & 460.6 \\
\hline & LT-128-4-21 & 10.97 & 100.2 & 0.91 & 428.9 \\
\hline $128 \mathrm{~mm}$ & LT-128-4-22 & 10.62 & 97.9 & 0.92 & 455.0 \\
\hline & LT-128-4-23 & 10.29 & 105.8 & 1.03 & 436.0 \\
\hline & LT-128-4-24 & 10.45 & 118.4 & 1.13 & 460.7 \\
\hline & LT-128-4-25 & 10.41 & 117.2 & 1.13 & 435.5 \\
\hline & LT-128-4-26 & 12.01 & 120.4 & 1.00 & 455.3 \\
\hline & LT-128-4-27 & 10.06 & 110.9 & 1.10 & 429.4 \\
\hline & LT-128-4-28 & 9.92 & 88.6 & 0.89 & 435.0 \\
\hline & LT-128-4-29 & 9.16 & 77.7 & 0.85 & 419.5 \\
\hline & LT-128-4-30 & 11.57 & - & - & 446.0 \\
\hline & LT-128-4-31 & 11.91 & 110.6 & 0.93 & 442.3 \\
\hline & LT-128-4-32 & 8.11 & 73.8 & 0.91 & 415.3 \\
\hline & LT-128-4-33 & 12.41 & 113.2 & 0.91 & 446.8 \\
\hline & LT-128-4-34 & 9.63 & 91.1 & 0.95 & 421.1 \\
\hline & LT-128-4-35 & 10.79 & 105.6 & 0.98 & 454.3 \\
\hline & LT-128-4-36 & 12.69 & - & - & 444.7 \\
\hline & LT-128-4-37 & 10.40 & 105.1 & 1.01 & 441.4 \\
\hline
\end{tabular}




\begin{tabular}{|l|l|l|l|l|l|}
\hline & LT-128-4-38 & 13.41 & 117.8 & 0.88 & 467.9 \\
\cline { 2 - 6 } & LT-128-4-39 & 9.88 & 99.8 & 1.01 & 424.0 \\
\cline { 2 - 6 } & LT-128-4-40 & 11.07 & 101.3 & 0.92 & 436.7 \\
\cline { 2 - 7 } & LT-128-4-41 & 12.29 & 123.2 & 1.00 & 473.0 \\
\cline { 2 - 6 } & LT-128-4-42 & 11.06 & 112.4 & 1.02 & 454.2 \\
\cline { 2 - 6 } & LT-128-4-43 & 9.87 & 93.7 & 0.95 & 451.9 \\
\hline
\end{tabular}

Table 2. Statistics of effective elastic modulus for four groups of specimens.

\begin{tabular}{|l|l|l|l|}
\hline Length $(\mathrm{mm})$ & Mean $(\mathrm{GPa})$ & SD $(\mathrm{GPa})$ & COV (\%) \\
\hline 2 & 10.3 & 2.02 & 19.6 \\
\hline 8 & 10.3 & 2.03 & 19.8 \\
\hline 32 & 10.6 & 1.91 & 18.0 \\
\hline 128 & 11.0 & 1.40 & 12.7 \\
\hline
\end{tabular}

Table 3. Results of goodness-of-fit tests for effective elastic modulus of spruce.

\begin{tabular}{|l|l|l|l|l|l|l|}
\hline \multirow{2}{*}{$\begin{array}{c}\text { Specimen } \\
\text { length (mm) }\end{array}$} & \multicolumn{2}{|c|}{ Normal } & \multicolumn{2}{c|}{ Lognormal } & \multicolumn{2}{c|}{ Weibull } \\
\cline { 2 - 7 } & AD & KS & AD & KS & AD & KS \\
\hline 2 & 0 & 0 & 0 & 0 & 0 & 0 \\
\hline 8 & 0 & 0 & 0 & 0 & 1 & 0 \\
\hline 32 & 0 & 0 & 0 & 0 & 0 & 0 \\
\hline 128 & 0 & 0 & 0 & 0 & 0 & 0 \\
\hline
\end{tabular}

Table 4. Statistics of local and effective elastic moduli of 128-mm specimens.

\begin{tabular}{|l|l|l|l|l|}
\hline & Number of data points & Mean $(\mathrm{GPa})$ & SD $(\mathrm{GPa})$ & COV (\%) \\
\hline Local modulus & 1280 & 11.2 & 1.84 & 16.4 \\
\hline Effective modulus & 40 & 11.0 & 1.40 & 12.7 \\
\hline
\end{tabular}


Table 5. Statistics of longitudinal tensile strength of spruce wood for specimens of different lengths.

\begin{tabular}{|l|l|l|l|l|}
\hline Specimen length $(\mathrm{mm})$ & Mean $(\mathrm{MPa})$ & SD $(\mathrm{MPa})$ & COV $(\%)$ & CWSEL mean (MPa) \\
\hline 2 & 112.9 & 15.9 & 14.1 & 176.3 \\
\hline 8 & 113.0 & 16.3 & 14.5 & 147.8 \\
\hline 32 & 111.6 & 18.6 & 16.7 & 123.9 \\
\hline 128 & 103.8 & 15.7 & 15.1 & 103.8 \\
\hline
\end{tabular}

Table 6. Results of goodness-of-fit tests for longitudinal tensile strength of spruce.

\begin{tabular}{|l|l|l|l|l|l|l|}
\hline \multirow{2}{*}{$\begin{array}{c}\text { Specimen } \\
\text { length (mm) }\end{array}$} & \multicolumn{2}{|c|}{ Weibull } & \multicolumn{2}{c|}{ Normal } & \multicolumn{2}{c|}{ Lognormal } \\
\cline { 2 - 7 } & AD & KS & AD & KS & AD & KS \\
\hline 2 & 0 & 0 & 0 & 0 & 0 & 0 \\
\hline 8 & 0 & 0 & 0 & 0 & 0 & 0 \\
\hline 32 & 0 & 0 & 0 & 0 & 0 & 0 \\
\hline 128 & 0 & 0 & 0 & 0 & 1 & 0 \\
\hline
\end{tabular}

Table 7. Statistics of strain to failure for spruce specimens under longitudinal tensile loading.

\begin{tabular}{|l|l|l|l|}
\hline $\begin{array}{l}\text { Specimen length } \\
(\mathrm{mm})\end{array}$ & Mean (\%) & SD (\%) & COV (\%) \\
\hline 2 & 1.14 & 0.17 & 15.2 \\
\hline 8 & 1.12 & 0.14 & 12.9 \\
\hline 32 & 1.08 & 0.12 & 11.4 \\
\hline 128 & 0.96 & 0.13 & 13.3 \\
\hline
\end{tabular}


Table 8. Results of goodness-of-fit tests for strain to failure of spruce.

\begin{tabular}{|l|l|l|l|l|l|l|}
\hline \multirow{2}{*}{$\begin{array}{c}\text { Specimen } \\
\text { length (mm) }\end{array}$} & \multicolumn{2}{|l|}{ Lognormal } & \multicolumn{2}{c|}{ Normal } & \multicolumn{2}{c|}{ Weibull } \\
\cline { 2 - 8 } & AD & KS & AD & KS & AD & KS \\
\hline $2 \mathrm{~mm}$ & 0 & 0 & 0 & 0 & 0 & 0 \\
\hline $8 \mathrm{~mm}$ & 0 & 0 & 0 & 0 & 0 & 0 \\
\hline $32 \mathrm{~mm}$ & 0 & 0 & 0 & 0 & 1 & 0 \\
\hline $128 \mathrm{~mm}$ & 0 & 0 & 0 & 0 & 0 & 0 \\
\hline
\end{tabular}




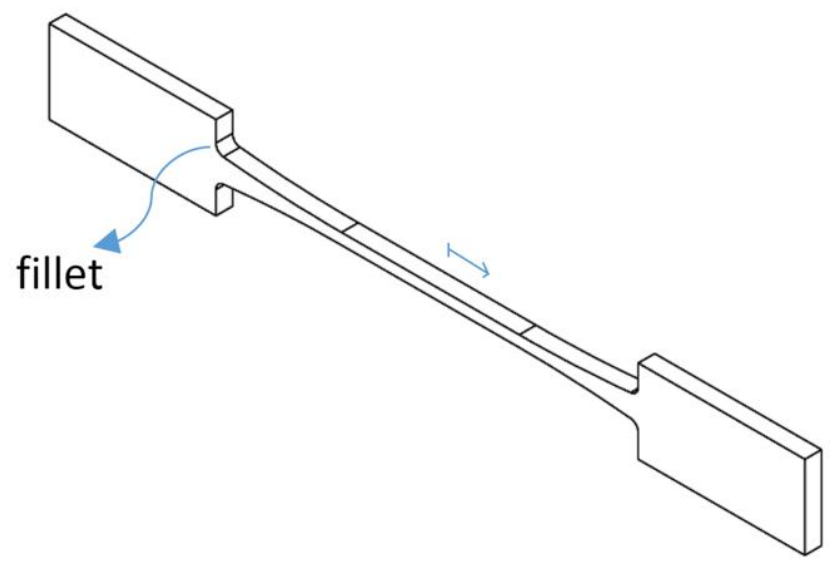

Fig. 1. Specimen geometry designed for tensile tests. The straight arrow shows the longitudinal timber direction.
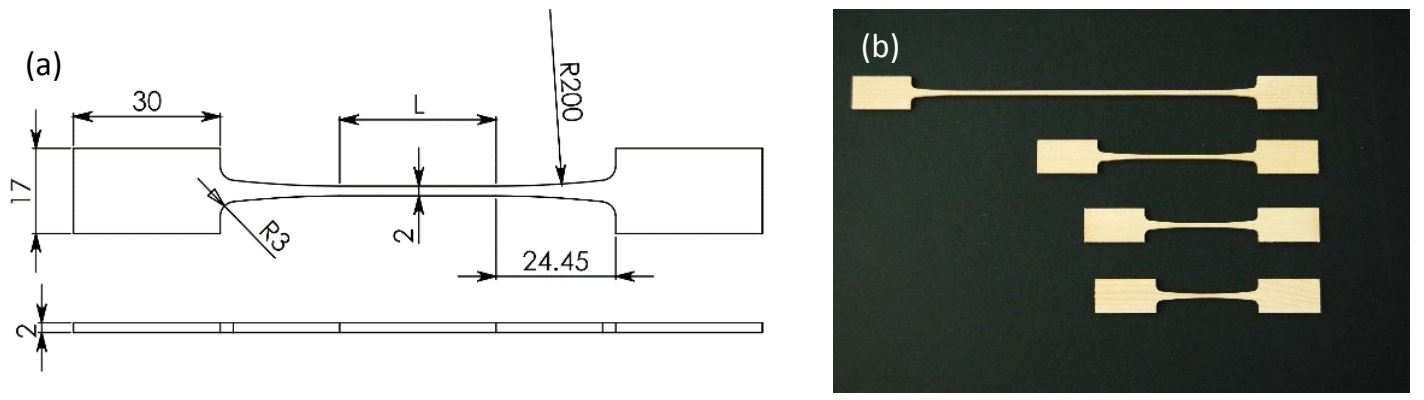

Fig. 2. a) Dimensions of specimen used for longitudinal tensile test, in millimeters b) Fabricated specimens of different lengths.

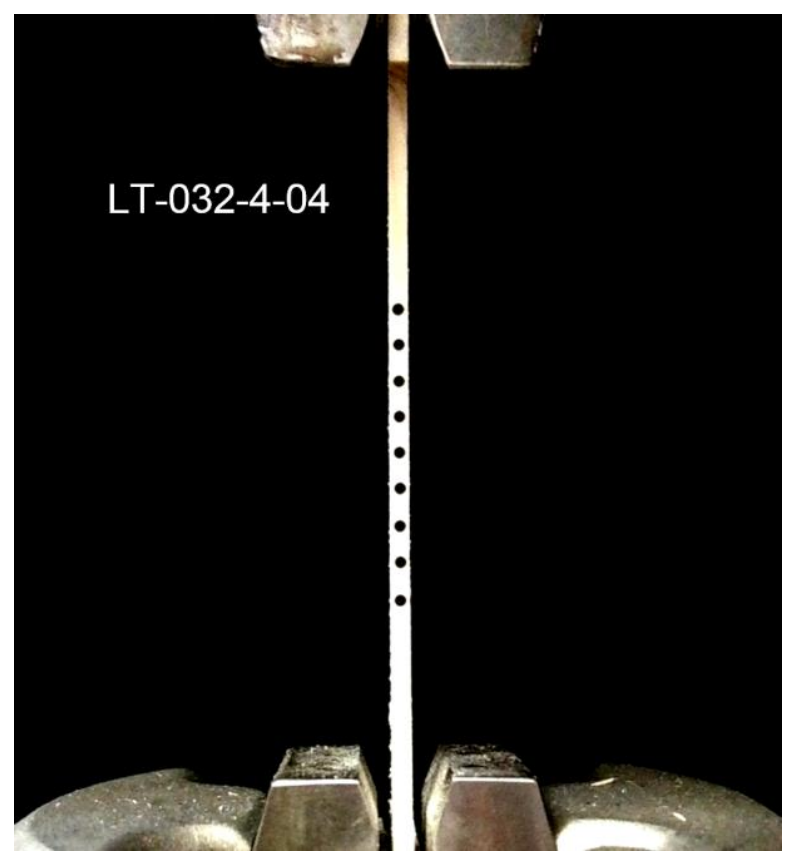

Fig. 3. Specimen of 32-mm nominal length with applied dots inside machine grips. 


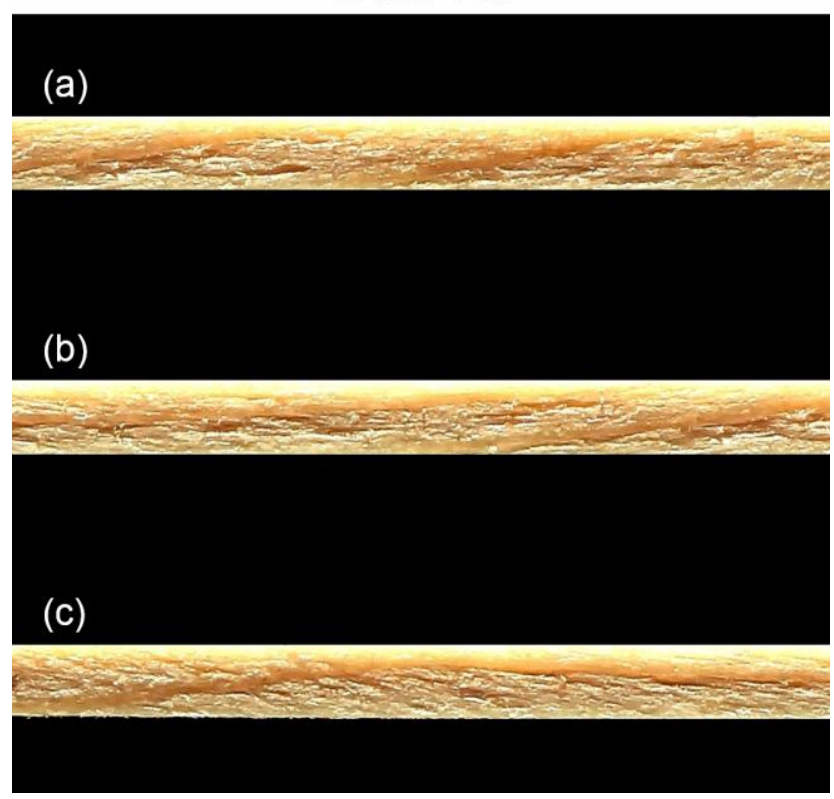

Fig. 4. Mesostructural features of spruce wood: a) fiber misalignment b) uneven growth ring thickness c) fiber waviness.

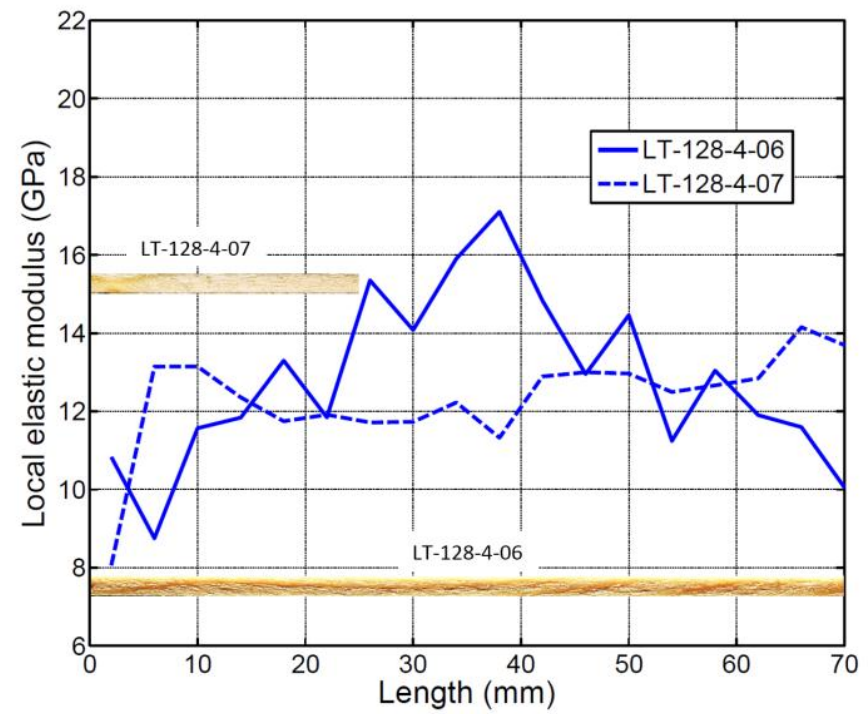

Fig. 5. Correspondence between mesostructure of spruce and variability of local elastic modulus. 


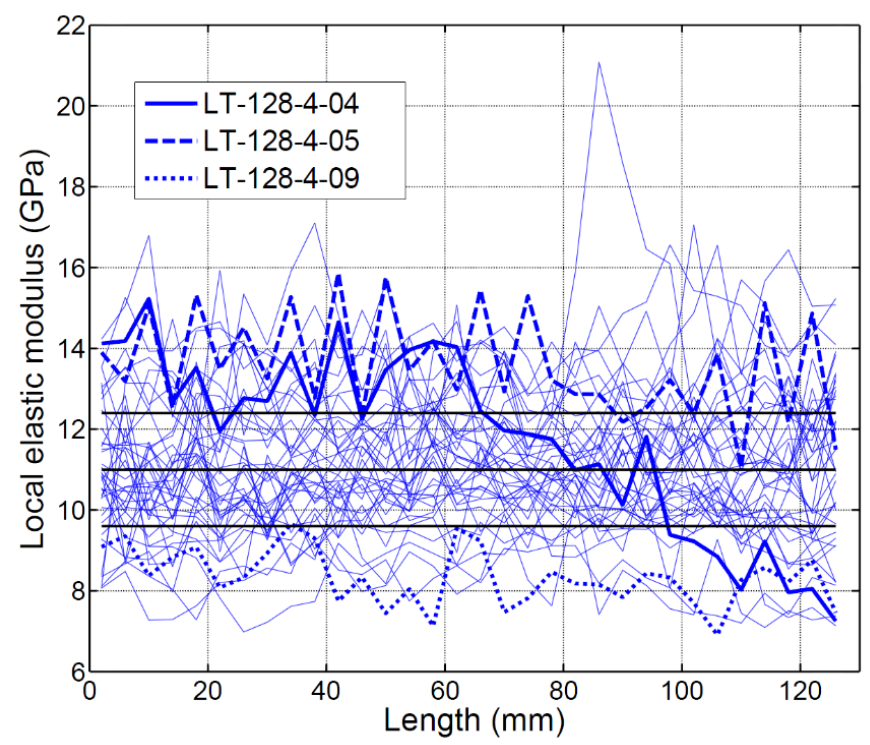

Fig. 6. Variation of local elastic modulus along length of 128-mm specimens.

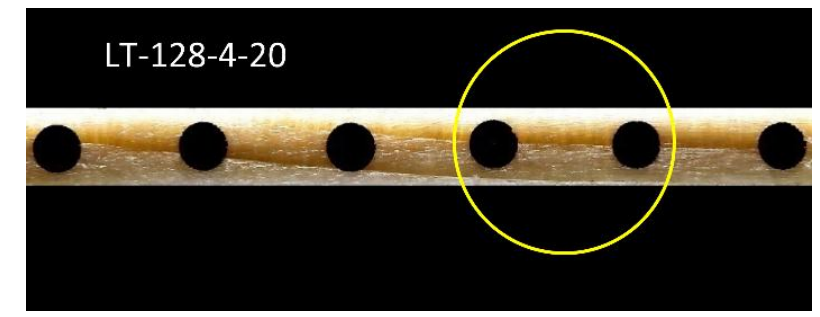

Fig. 7. Segment with highest measured local elastic modulus (indicated by a circle). 


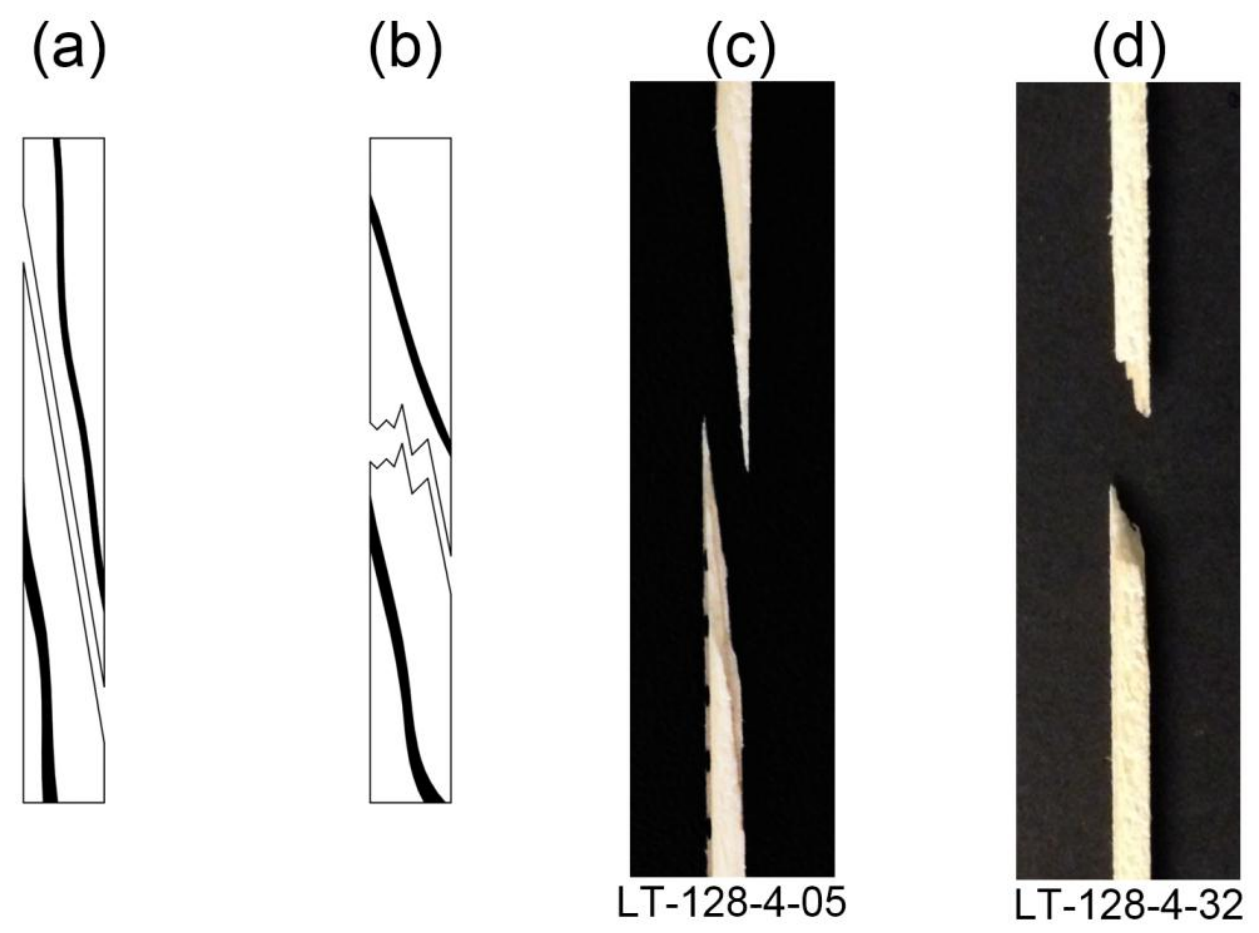

Fig. 8. a and b) Schematic illustration of two failure modes; c and d) Typical specimen failures.

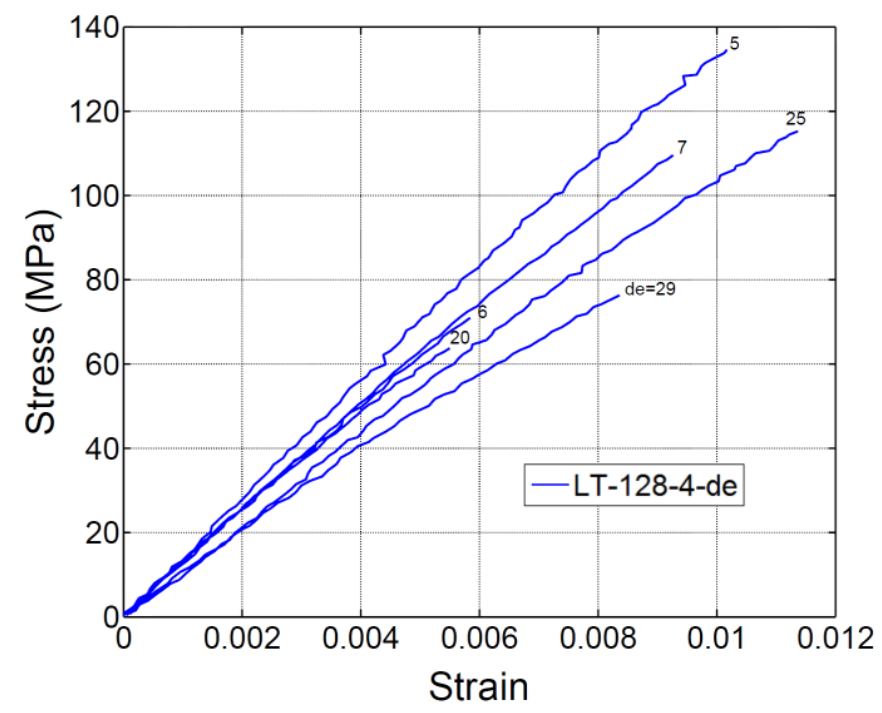

Fig. 9. Typical longitudinal tensile stress-strain curves of spruce wood. 


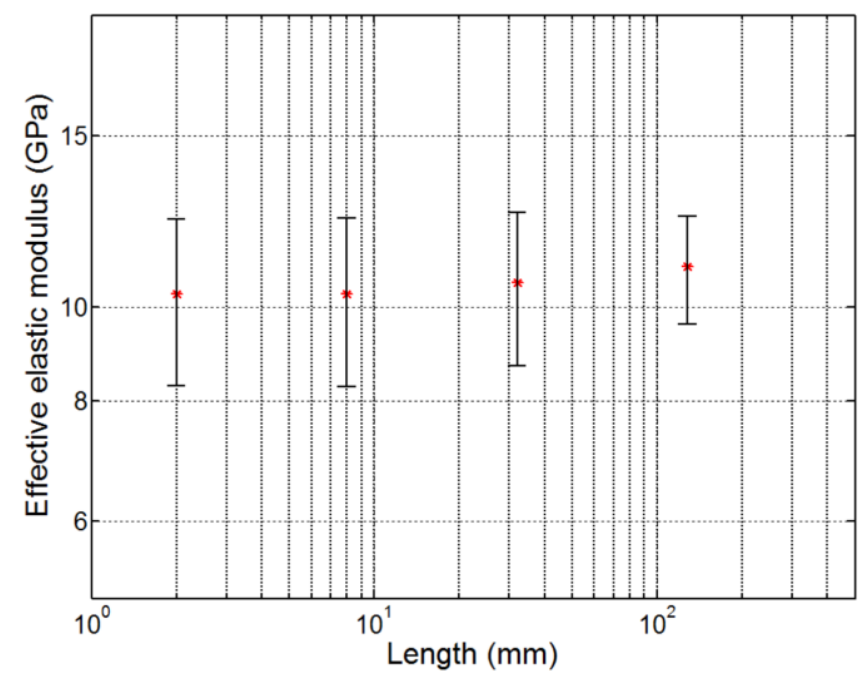

Fig. 10. Mean value of effective elastic modulus for specimens of different lengths. Error bars indicate standard deviation for each length.

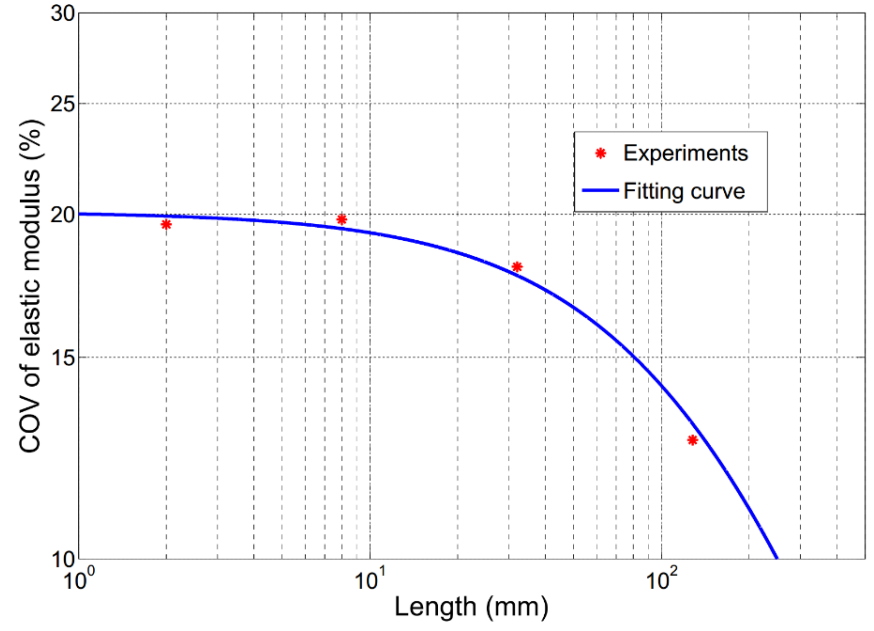

Fig. 11. COV of effective elastic modulus as function of specimen length. 


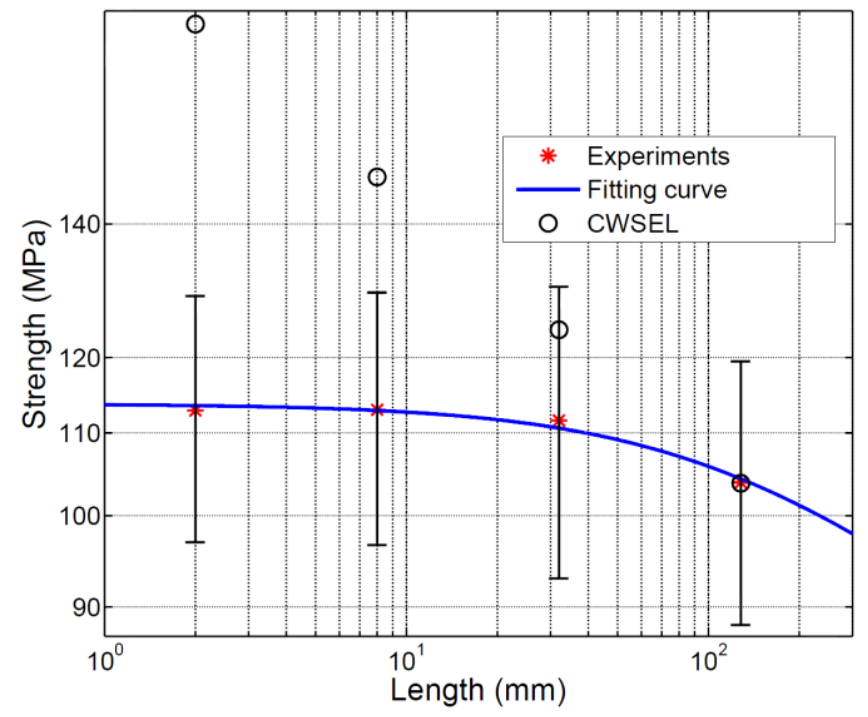

Fig. 12. Mean value for longitudinal tensile strength vs. specimen length for spruce wood. Error bars indicate standard deviation for each length.

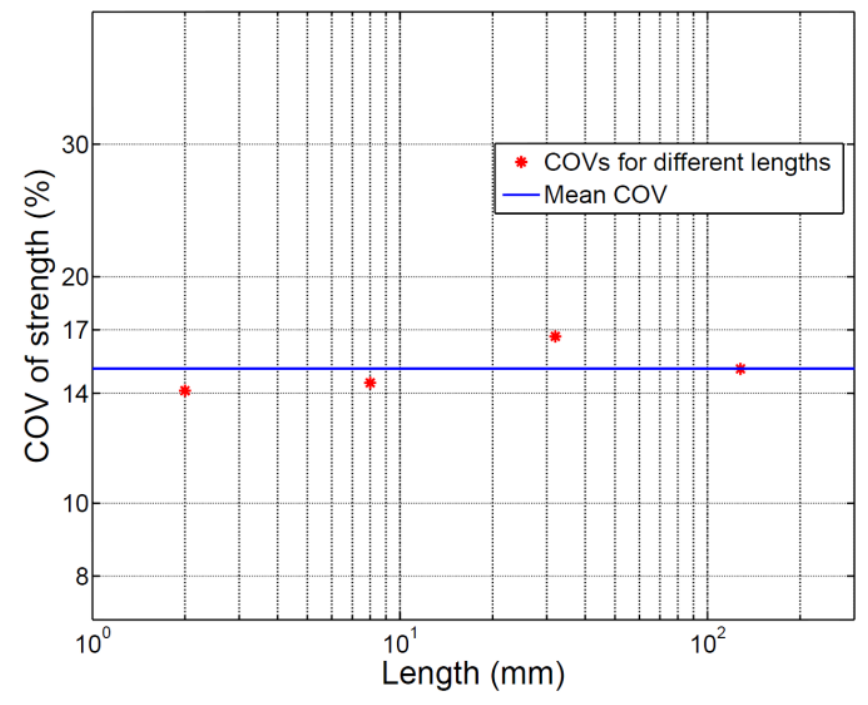

Fig. 13. COV of strength for specimens of different lengths. 


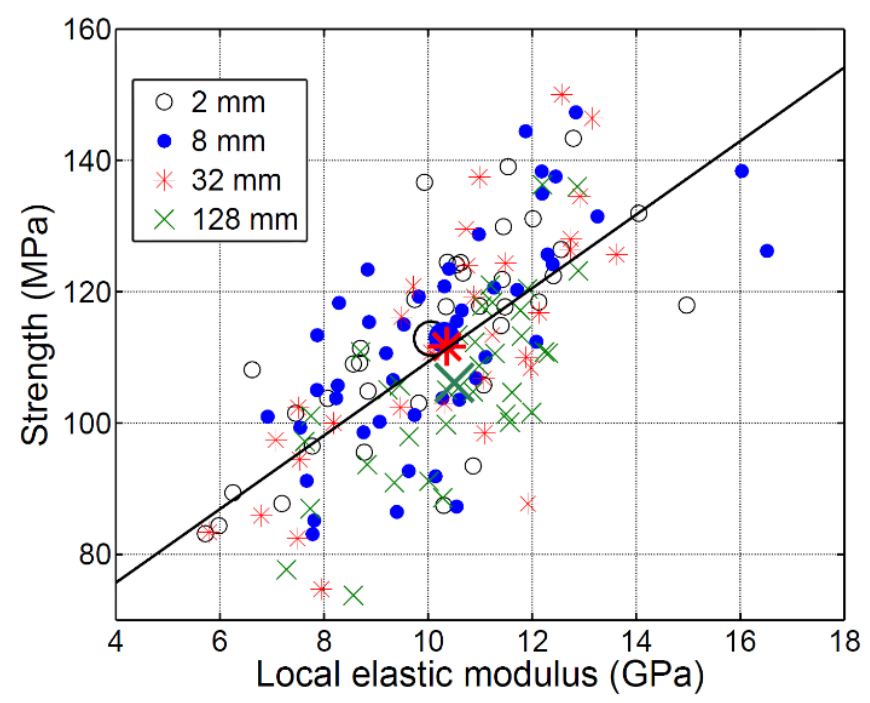

Fig. 14. Correlation between local elastic modulus and tensile strength in parallel-to-grain direction.

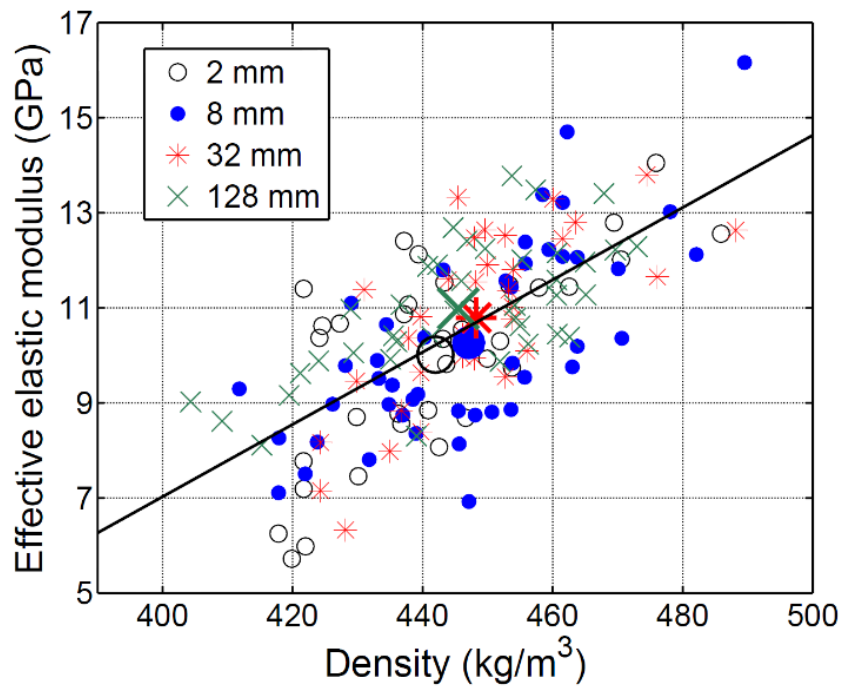

Fig. 15. Correlation between density and effective elastic modulus. 


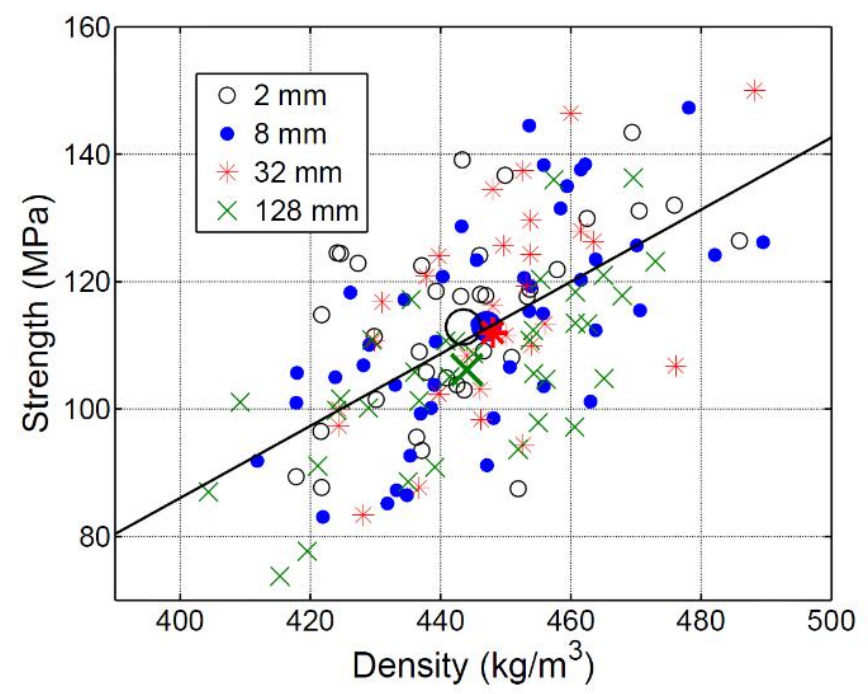

Fig. 16. Correlation between density and strength. 